Оригинальная статья/Original article

УДК 334.75

DOI: http://doi.org/10.20914/2310-1202-2017-2-361-365

Аутсорсинг и государственно-частное партнерство

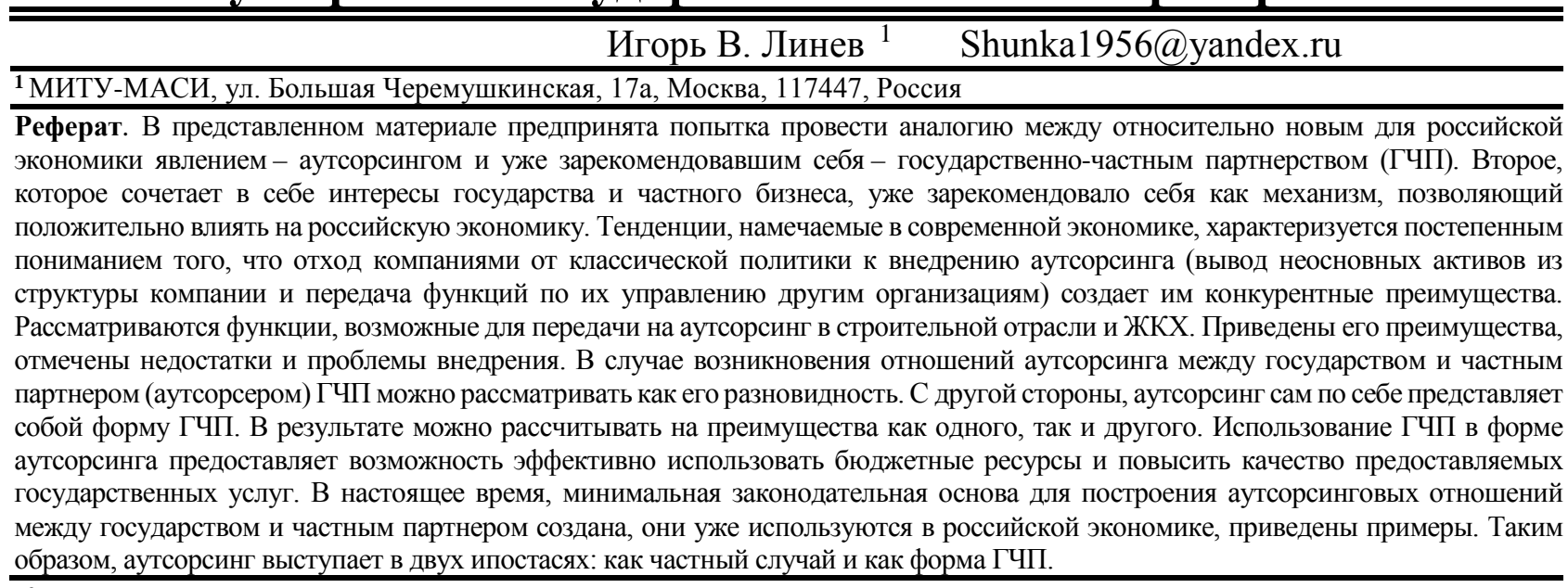

Ключевые слова: аутсорсинг, государственно-частное партнерство, организация-аутсорсер

\title{
Outsourcing and public-private partnership
}

\begin{tabular}{l}
\hline Igor V. Linev 1 Shunka1956@yandex.ru \\
Summary. In the presented material an attempt to draw an analogy between the phenomenon, rather new to the Russian economy, - \\
outsourcing and already proved - the public-private partnership (PPP) is made. The second which combines interests of the state and private \\
business has already proved as the mechanism allowing to influence positively the Russian economy. The tendencies planned in modern \\
economy it is characterized by gradual understanding that withdrawal by the companies from classical policy to outsourcing introduction (a \\
conclusion of non basic assets from structure of the company and transfer of function on their management to other organizations) creates him \\
competitive advantages. Functions, possible for transfer on outsourcing, in particular, in construction branch and housing and communal \\
services are considered. His advantages are given, shortcomings and problems of introduction are noted. In case of the relations of outsourcing \\
between the state and the private partner (outsourcer) of PPP it is possible to consider as his version. On the other hand, outsourcing in itself \\
represents a form of PPP. As a result it is possible to count on advantages as one, and another. Use of PPP in the form of outsourcing gives an \\
opportunity to effectively use the budgetary resources and to increase quality of the provided state services. Now, the minimum legislative \\
basis for creation of the outsourcing relations between the state and the private partner is created, they are already used in the Russian economy, \\
examples are given. Thus, outsourcing acts in two forms: as special case and as form of PPP. \\
Keywords: outsourcing, public-private partnership, organization-outsourcer \\
\hline \hline
\end{tabular}

\section{Введение}

Тенденция, намечаемая в современной экономике, характеризуется тем обстоятельством, что наемный труд вытесняется услугами организаций-аутсорсеров. Аутсорсинг, в общем случае, представляет собой передачу компанией, на основании договора, определенных бизнеспроцессов на обслуживание другой организации (аутсорсеру). Постепенно приходит понимание того, что компании, придерживающиеся классической HR-политики ${ }^{1}$ (создание благоприятных условий труда, обеспечение возможности продвижения по службе и уверенности в завтрашнем дне) и использующие исключительно in-house (англ. работа в офисе), существенно

${ }^{1}$ От англ. Human Resource - человеческие ресурсы Для цитирования

Линев И.В. Аутсорсинг и государственно-частное партнерство // Вестник ВГУИТ. 2017. Т. 79. № 2. С. 361-365. doi:10.20914/23101202-2017-2-361-365 будут проигрывать аналогичным, состоящим из СЕО (англ. высшее должностное лицо) - разрабатывающих стратегию развития и принимающих решения на высшем уровне; и соre team (англ. костяк коллектива). Последние и координируют работу аутсорсера [1].

Аутсорсинг, в классическом понимании, является деятельностью внешних исполнителей, которые, после заключения гражданско-правового договора и на его основании, осуществляют функции, в которых нуждается та или иная компания. Отметим, что в настоящее время эти функции, как правило, не являются основными для рассматриваемой компании. То есть возникает партнерство, которое позволяет ей сосредоточить

For citation

Linev I.V. Outsourcing and public-private partnership. Vestnik VGUIT [Proceedings of VSUET]. 2017. vol. 79. no. 2. pp. 361-365. (in Russian). doi:10.20914/2310-1202-2017-2-361-365 
усилия на основной деятельности, и, следовательно - достигать более высоких результатов, при этом зачастую осуществляется экономия средств. Если одной из сторон является бюджетная организация, то можно говорить о государственно-частном партнерстве (ГЧП) совместной деятельности государственного и частного партнеров для достижения общей цели.

\section{Основная часть}

Если юридически закрепить разрешение передачи государством сторонним организациям ${ }^{2}$ отдельные вопросы подготовки и реализации проектов ГЧП, то можно рассчитывать на повышение эффективности государственного управления. Это подтверждается международным опытом. К таким вопросам могут быть отнесены: разработка необходимой документации, оформление соглашений (по соответствующей форме ГЧП), а также подготовка и, возможно, непосредственная реализация проекта. На первом этапе, на аутсорсинг можно перевести некоторую часть разработок, продажи, контент, часть колл-центра, пиар и другие процессы.

Например, если в жилищно-коммунальном хозяйстве (ЖКХ) подготовкой и реализацией проекта ГЧП будут заниматься муниципальные унитарные предприятия (МУП), которые имеют непосредственное отношение к коммунальным объектам, то способ организации этого проекта будет более эффективным. Необходимость названного юридического закрепления обусловлена тем обстоятельством, что в российском законодательстве [7] предусмотрено, что отдельные права и обязанности государственного партнера, могут осуществляться органами и/или указанными в сноске юридическими лицами, уполномоченными этим партнером. Передача некоторых функций государственного партнера (при реализации ГЧП) третьим лицам - предприятиям и организациям, подконтрольным ему уже осуществляется в Российской Федерации при реализации наиболее распространенной формы ГЧП - концессий. Так, государственная компания «Автодор» выполняет функции концедента в области автомобильнодорожного хозяйства.

Функции, возможные для передачи на аутсорсинг, например, в строительной отрасли и ЖКХ, могут быть следующие:

- эксплуатация, содержание и ремонт зданий, сооружений;

- установка, обслуживание и управление системами охраной и пожарной сигнализации,

${ }^{2}$ Согласно российскому законодательству [2] не могут являться частными партнерами: государственные унитарные предприятия (ГУП) и МУПы, государственные и муниципальные учре- кондиционирования, вентиляции, а также системами связи, интернет-, радио-, телекоммуникаций;

- эксплуатация, обслуживание и ремонт инженерных и технических систем зданий, сооружений;

- организация учета потребления теплои электроэнергии, воды;

- обеспечение оптимизации энергои водопотребления;

- приобретение, доставка на объект и установка оборудования, компьютерной и иной техникой, мебели, хозяйственного инвентаря и т. п.

Рассматривая достоинства аутсорсинга, отметим наиболее важные, на наш взгляд, из них.

Решать возникшую задачу с помощью аутсорсинга дешевле, по крайней мере, по четырем причинам. Во-первых, при его использовании оплачивается готовый результат, а не повременная работа сотрудников. Во-вторых, отпадает необходимость оплаты отпускных, больничных, декретных и т. д. В-третьих, не нужно обустраивать рабочие места (в том числе - обеспечение их дорогостоящей компьютерной и оргтехникой) вновь нанимаемых (для решения возникшей задачи) сотрудников и ожидать когда они адаптируются в новом коллективе. В-четвертых, нет необходимости нести расходы по найму и увольнению, обучению, а также уплачивать налоги. Постепенный вывод определенных бизнес - процессов за штат сокращает фонд оплаты труда и операционные расходы. Напротив, кажущийся эффект от того, что чем больше штатных сотрудников, тем быстрее можно выйти на положительные показатели и работа будет выполняться эффективнее, будет сопровождаться ростом привлекаемых средств.

Поскольку, как отмечалось выше, при использовании аутсорсинга оплачивается готовый результат, постольку можно говорить о его эффективности, выражающейся в реальности реализации принципа «не сделал - не получил». При этом в расчет не принимаются чисто человеческие факторы. Штатный же сотрудник не всегда мотивирован на совершенствование в достижении результатов. Для управления его мотивацией необходим постоянный квалифицированный менеджмент, а для этого требуется время и опять же средства.

Аутсорсинг весьма гибкий инструмент и с этим его качеством связана появляющаяся у организации, которая им воспользовалась, возможность решать непрофильные для нее задачи. Другими словами, бизнес может постоянно

ждения, публично-правовые компании, хозяйственные товарищества и некоммерческие организации, созданные государством или подконтрольные ему. 
увеличивать поток задач в той или иной сфере, то есть масштабироваться.

Оценка преимуществ аутсорсинга (согласно данным консалтинговой компании «Deloitte» [12]) в цифровом выражении представлена на рисунке 1.

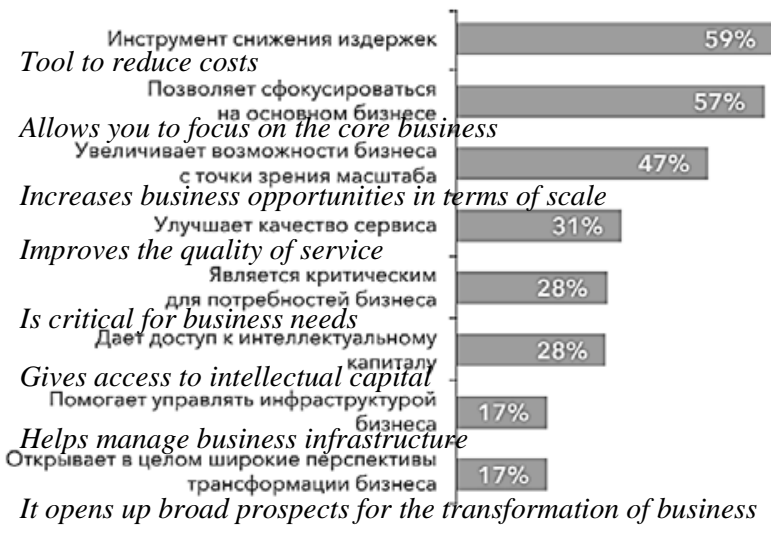

Рисунок 1. Причины, инициирующие аутсорсинг

Figure 1. Reasons for initiating outsourcing

Если ГЧП рассматривать как отношения «best-of-bothworlds» (англ. «Мы лучшие из лучших»), в которых участвуют самые квалифицированные частные организации, а также надежный партнер-заказчик - государство [6], а при этом аутсорсинг - делегирование производства товаров и оказание услуг агентом (государством) внешнему производителю (частному бизнесу) от имени принципала (общества) [4], то становится правомерным проведение аналогии между ними. То есть при аутсорсинге между государством и частным партнером (аутсорсером) ГЧП можно рассматривать как его разновидность. С другой стороны, аутсорсинг сам по себе представляет собой форму ГЧП.

Итак, используя аутсорсинг для реализации проектов ГЧП, стороны партнерства получают несомненные выгоды. С другой стороны, как отмечалось выше, аутсорсинг сам по себе является формой ГЧП, так как основан на тех же принципах, представленных в таблице 1. При таком подходе можно рассматривать преимущества для сторон аутсорсинговой сделки [3], представленные в таблице 2 .

Таблица 1.

Реализация принципов ГЧП при аутсорсинге

Table 1.

Implementation of PPP principles in outsourcing

\begin{tabular}{|c|c|}
\hline Принципы ГЧП | Principles of PРP & \multirow{7}{*}{$\begin{array}{l}\text { В аутсорсинге принципы ГЧП реализуются } \\
\text { исходя из определения его как «передача } \\
\text { организацией, на основании договора* } \\
\text { определённых бизнес-процессов или про- } \\
\text { изводственных функций на обслуживание } \\
\text { другой компании, специализирующееся в } \\
\text { соответствующей области } \\
\text { In outsourcing the principles of PPP are real- } \\
\text { ized proceeding from the definition of it as the } \\
\text { transfer by the organization, on the basis of } \\
\text { the contract, * of certain business processes or } \\
\text { production functions to the service of another } \\
\text { company, specializing in the relevant field }\end{array}$} \\
\hline $\begin{array}{l}\text { Открытость и доступность информации | Openness and accessi- } \\
\text { bility of information }\end{array}$ & \\
\hline Обеспечение конкуренции | Ensuring competition & \\
\hline $\begin{array}{l}\text { Отсутствие дискриминации, равноправие сторон соглашения | } \\
\text { Absence of discrimination, equality of parties to the agreement }\end{array}$ & \\
\hline $\begin{array}{l}\text { Добросовестное исполнение сторонами соглашения обязательств } \\
\text { по соглашению | Conscientious performance by the parties to the } \\
\text { agreement of obligations under the agreement }\end{array}$ & \\
\hline $\begin{array}{l}\text { Справедливое распределение рисков и обязательств между сто- } \\
\text { pонами |Fair distribution of risks and liabilities between the parties }\end{array}$ & \\
\hline Свобода заключения соглашения | Freedom to enter into an agreem & \\
\hline
\end{tabular}

*B договоре д. б. предусмотрены принципы, представленные в левой части таблицы (* The agreement should provide for the principles presented on the left side of the table)

Таблица 2.

Преимущества аутсорсинга

Table 2 .

Advantages of outsourcing

\begin{tabular}{|c|c|}
\hline Для государства: | For the & Для частного партнера: | For a private partner: \\
\hline $\begin{array}{l}\text { Снижение издержек и повышени } \\
\text { проекта | Reduce costs and improve }\end{array}$ & $\begin{array}{l}\text { Долгосрочный и стабильный доход | Long-term and } \\
\text { stable income }\end{array}$ \\
\hline $\begin{array}{l}\text { Повышение рентабельности за счет концентрации на про- } \\
\text { фильных высокорентабельных функциях | Increase profitability } \\
\text { due to concentration on profiled highly profitable functions }\end{array}$ & \multirow{2}{*}{$\begin{array}{l}\text { Возможность изменить формат работы с заказчиком } \\
\text { ради наиболее продуктивного сотрудничества | The } \\
\text { opportunity to change the format of work with the cus- } \\
\text { tomer for the most productive cooperation } \\
\text { Для частного партнера: | For a private partner: }\end{array}$} \\
\hline $\begin{array}{l}\text { Увеличение возможности гибко реагировать на изме- } \\
\text { нения внешней среды | Increase the ability to respond } \\
\text { flexibly to changes in the environment }\end{array}$ & \\
\hline
\end{tabular}

Для связи с редакцией: post@vestnik-vsuet.ru 
Указанные преимущества проявятся в полной мере в том случае, если взаимодействие осуществляется с состоявшимися предпринимателями, имеющими большой опыт в конкретной области. Основной вопрос состоит в том, как выбрать такого аутсорсера, так как его экспертиза (компании, которая постоянно выполняет задачи в этой области и сталкивается с большим количеством кейсов) намного сложнее, чем аналогичная, проводимая при приеме сотрудников в штат. То есть решить вторую задачу проще, чем первую и, возможно, по этой причине аутсорсинг не находит, пока, широкого распространения в российской экономике.

Основной проблемой внедрения аутсорсинга является использование в большинстве случаев только одной формы ГЧП - государственного (муниципального) заказа. Сама по себе система формирования, финансового обеспечения и контроля выполнения государственного (муниципального) заказа, хотя законодательно и жестко регламентирована, но не отработана или имеет существенную коррупционную составляющую. Естественно, все это возникает и при использовании аутсорсинга. К этому добавляются вопросы о том, какие государственные функции не могут быть переданы на аутсорсинг, кто будет устанавливать эти границы, какие для этого требуются законодательные акты, и на каком уровне они должны быть приняты. Заказываемые услуги (реализация «кусочков» функций и отдельных административных процессов) часто сложны по своей структуре и механизмам реализации. Они требуют четкой регламентации и стандартизации со стороны заказчика, а также четкого и своевременного планирования потребности в этих услугах. То есть орган-заказчик должен отчетливо представлять, что он передает на аутсорсинг, в каком количестве и какое качество хотел бы получить в итоге [2].

Целесообразность внедрения этой формы ГЧП определяют с точки зрения экономического воздействия, которое неразрывно связано с экономией средств и времени, что обеспечивает создание условий для повышения качества услуг, а также происходит перераспределение денежных средств, что позволяет более эффективно использовать имеющиеся ресурсы [5]. Использование ГЧП в форме аутсорсинга предоставляет возможность эффективно использовать бюджетные ресурсы и повысить качество предоставляемых государственных услуг. Первое обусловлено неправомерностью тезиса о больших гонорарах, взимаемых сторонними организациями (по сравнению с зарплатами государственных служащих) за предоставляемые услуги. На самом деле оплату труда государственных служащих нельзя рассматривать только как заработную плату в денежном выражении. Следует также учитывать и специальное медицинское обслуживание, и особые условия пенсионного содержания и т. п. Второе - отсутствием у государственных структур стимула повышать производительность труда, в том числе за счет уменьшения количества сотрудников, что в обязательном порядке (от этого зависит прибыль) присутствует у внешнего поставщика (аутсорсера) [13].

В настоящее время, минимальная законодательная основа $[8,9]$ для построения аутсорсинговых отношений между государством и частным партнером создана. И такая практика уже существует, например, в ФАС России [10] или в Федеральном казначействе [11], а также на региональном уровне. Следует подчеркнуть, что здесь имеется в виду вновь вводимый в государственном управлении термин «аутсорсинг административных процессов», так как передача функций целиком за пределы системы исполнительной власти законодательно не предусмотрена, и если функции, являющиеся прерогативой государства, будут полностью исполнять частный партнер, то речь об аутсорсинге не идет. И здесь опять встает вопрос, какую часть этих функций можно передавать на аутсорсинг. Опыт работы по приему и обработке документов многофункциональными центрами оказания государственных услуг (МФЦ), сотрудники которых не являются государственными служащими, показывает, что эта часть может быть значительной. Не могут быть переданы на аутсорсинг только те процессы, про которые в законодательстве сказано «исполняет государственный служащий» [2].

\section{Заключение}

Резюмируя вышесказанное, отметим, что аутсорсинг выступает в двух видах: как частный случай и как форма ГЧП, или между ними можно проводить аналогию. Различие этих экономических явлений проявляется в сферах их применения. ГЧП - это, прежде всего, крупномасштабные, высокотехнологичные проекты имеющие, как правило, макроэкономическое значение. Аутсорсингрутинные бизнес-процессы. 


\section{ЛИТЕРАТУРА}

1 Bachlechner D., Thalmann S., Manhart M. Auditing service providers: supporting auditors in cross-organizational settings // Managerial Auditing Journal. 2014. T. 29. №. 4. C. 286-303.

2 Елисеенко В. Госфункции на аутсорсинге // Казенные учреждения: учет, отчетность, налогообложение. 2012. № 6.

3 Осокина И.В. Государственно-частное партнерство и Аутсорсинг в государственной деятельности: сравнительный анализ // Научнопрактический журнал Современная наука: Актуальные проблемы теории и практики. Серия ЭКОНОМИКА и ПРАВО. 2015. № 3-4.

4 Шадрина Е.В., Виноградов Д.В. Государственно-частное партнерство как форма организации бизнеса // Вопросы государственного и муниципального управления. 2012. № 4.

5 Шрайнер О.О. Аутсорсинг в рамках государственно-частного партнерства в сфере здравоохранения // Актуальные вопросы экономических наук. 2017. № 56.

6 Bindal A., Sharma M. Public-Private Partnership // International Journal of Research (IJR). August, 2014.

7 Федеральный закон от 13 июля 2015 г. № 224-Ф3 «О государственно-частном партнерстве, муниципально-частном партнерстве в Российской Федерации и внесении изменений в отдельные законодательные акты Российской Федерации».

8 Распоряжение Правительства Российской Федерации от 25 октября 2005 г. № 1789-р.

9 Распоряжение Правительства Российской Федерации от 30 июня 2010 г. № 1101-р.

10 Приказ ФАС России от 24 октября 2006 г. № 271.

11 Приказ Казначейства России от 20 июля 2011 г. № 302.

12 Официальный сайт консалтинговой компании «Deloitte». URL: www.deloitte.com/

13 Mansor M. F. и др. The effect of cost reduction and business strategy on human resource outsourcing practicing: A study of Malaysian government link company // Technology Management and Emerging Technologies (ISTMET), International Symposium on. IEEE, 2015. C. 238-242.

14Lovchikova E.I., Sukhocheva N.A. Implementation of the outsourcing concept in the regional agro-industrial complex // Russian Journal of Agricultural and Socio-Economic Sciences. 2017. T. 65. № 5. C. 72-29.

\section{СВЕДЕНИЯ ОБ АВТОРАХ}

Игорь В. Линев к.э.н., профессор, кафедра «Строительство и городское хозяйство», МИТУ-МАСИ, ул. Большая Черемушкинская, 17a, Москва, 117447, Россия, Shunka1956@yandex.ru

\section{КРИТЕРИЙ АВТОРСТВА}

Игорь В. Линев Полностью подготовил рукопись и несет ответственность за плагиат

\section{КОНФЛИКТ ИНТЕРЕСОВ}

Автор заявляет об отсутствии конфликта интересов.

ПОСТУПИЛА 29.03.2017

ПРИНЯТА В ПЕЧАТЬ 22.05.2017

\section{REFERENCES}

1 Bachlechner D., Thalmann S., Manhart M. Auditing service providers: supporting auditors in cross-organizational settings. Managerial Auditing Journal. 2014. vol. 29. no. 4. pp. 286-303.

2 Eliseenko V. Garfunkle on outsourcing. Kazennye uchrezhdeniya: uchet, otchetnost', nalogooblozhenie [Public institution: accounting, reporting, taxation]. 2012. no. 6. (in Russian).

3 Osokina I.V. Public-private partnerships and Outsourcing of government activities: a comparative analysis. Nauchno-prakticheskii zhurnal Sovremennaya nauka: Aktual'nye problemy teorii i praktiki. Seriya Ekonomika i Pravo [Scientific-practical journal of Modern science: Actual problems of theory and practice. Series Economics and Law]. 2015. no. 3-4. (in Russian).

4 Shadrina E.V., Vinogradov D.V. Public-private partnership as a form of business organization. Voprosy gosudarstvennogo i munitsipal'nogo upravleniya [Issues of state and municipal management]. 2012. no. 4. (in Russian).

5 Shrainer O.O. Outsourcing through publicprivate partnerships in the health sector. Aktual'nye voprosy ekonomicheskikh nauk [Topical issues of economic Sciences]. 2017. no. 56. (in Russian).

6 Bindal A., Sharma M. Public-Private Partnership. International Journal of Research (IJR). August, 2014.

7 Federal'nyj zakon ot 13 ijulja 2015 g. no. 224 FZ "O gosudarstvenno-chastnom partnerstve, municipal'no-chastnom partnerstve v Rossijskoj Federacii i vnesenii izmenenij $\mathrm{v}$ otdel'nye zakonodatel'nye akty Rossijskoj Federacii”. (in Russian)

8 Rasporjazhenie Pravitel'stva Rossijskoj Federacii ot 25 oktjabrja 2005 g. no. 1789 r. (in Russian)

9 Rasporjazhenie Pravitel'stva Rossijskoj Federacii ot 30 ijunja 2010 g. no. 1101 r. (in Russian)

10 Prikaz FAS Rossii ot 24 oktjabrja 2006 g. no. 271. (in Russian)

11 Prikaz Kaznachejstva Rossii ot 20 ijulja 2011 g. no. 302. (in Russian)

12 The official site of the consulting company Deloitte. Available at: www.deloitte.com (in Russian)

13 Mansor M.F. et al. The effect of cost reduction and business strategy on human resource outsourcing practicing: A study of Malaysian government link company. Technology Management and Emerging Technologies (ISTMET), International Symposium on. IEEE, 2015. pp. 238-242.

14 Lovchikova E.I., Sukhocheva N.A. Implementation of the outsourcing concept in the regional agro-industrial complex. Russian Journal of Agricultural and Socio-Economic Sciences. 2017. vol. 65. no. 5. pp. 72-29. (in Russian).

\section{INFORMATION ABOUT AUTHORS}

Igor V. Linev candidate of economical sciences, professor, Construction and municipal economy department, MITUMASI, Bolshaya Cheremushkinskaya str., 17a, Moscow, 117447, Russia, Shunka1956@yandex.ru

\section{CONTRIBUTION}

Igor V. Linev Completely prepared the manuscript and is responsible for plagiarism

\section{CONFLICT OF INTEREST}

The author declare no conflict of interest. RECEIVED 3.29.2017 ACCEPTED 5.22.2017 